CAPÍTULO 3

\title{
Caracterização dos compostos voláteis e óleos essenciais de sete-capotes (Campomanesia guazumifolia (Cambess.) O. Berg)
}

Raquel Guidetti Vendruscolo, Roger Wagner, Bruna Tischer, Daniele de Freitas Ferreira, Francine Novack Victoria

https://doi.org/10.4322/mp.978-65-991393-3-8.c3

\section{Resumo}

O sete-capotes (Campomanesia guazumifolia (Cambess.) O. Berg) é um fruto nativo típico da América do Sul, pertencente à família das Mirtáceas, de cor verdeamarelado, pequeno, de polpa subglobosa que possui sabor e aroma intensos. Contudo, existem poucos relatos na literatura sobre a caracterização da fração volátil de sete-capotes. Nesse sentido, o objetivo deste estudo foi analisar os compostos voláteis presentes na polpa e dos óleos essenciais das cascas e sementes dos frutos de sete-capotes. As amostras foram coletadas na flora nativa da cidade de Tuparendi, Rio Grande do Sul - Brasil. Os compostos voláteis da polpa foram extraídos pela técnica de SPME (DVB/Car/PDEM). Os óleos essenciais foram extraídos a partir de $100 \mathrm{~g}$ de casca e $50 \mathrm{~g}$ de semente em aparato do tipo Clevenger. Ambas frações voláteis foram dessorvidas em cromatógrafos de fase gasosa equipado com um detector de ionização de chama (CG-DIC) e espectrômetro de massas (CG/EM) para a quantificação e identificação, respectivamente. Foram identificados 81 compostos no headspace da polpa pertencentes a diferentes classes químicas. A classe dos terpenos foi a que apresentou maior número de compostos, como (E) $\beta$-ocimeno, Lmentol e linalol. Enquanto o 1- hexanol, o hexanal e o (E)-2-hexenol, compostos de degradação dos ácidos linoleico e linolênico, foram os compostos majoritários, representando $41,58 \%$ da área total do cromatograma. Foram detectados cerca de 60 compostos nos óleos essenciais de sete-capotes, destes 24 foram identificados. Os óleos das cascas e sementes foram qualitativamente semelhantes, apresentando predominância de monoterpenos hidrocarbônicos. Os compostos majoritários foram $\beta$ ocimeno (Z), o nerolidol (E) e o limoneno. Assim, o perfil volátil de sete-capotes se mostrou rico em compostos descritores de odores herbáceo, amadeirado e floral.

Palavras-chave: cromatografia gasosa, micro extração em fase sólida, mirtácea, óleos essenciais.

\section{Introdução}

O Brasil apresenta a flora mais diversificada do mundo, constituída por uma infinidade de espécies frutíferas nativas com potencial para alimentação e industrialização. Porém, muitas dessas espécies são pouco exploradas e têm seu consumo restrito as áreas em que se desenvolvem naturalmente (INFANTE et al., 2016). Por outro lado, há um grande interesse por parte dos consumidores em frutos de sabores e aromas 
diferenciados, principalmente quando aliados a elevado valor nutricional e a propriedades funcionais (AYSELI; AYSELI, 2016).

A família das Mirtáceas se destaca no Brasil por apresentar o maior número de espécies com potencial alimentar, mas sua exploração comercial ainda é restrita (PEREIRA et al., 2012). A goiaba (Psidium guajava L.), a pitanga (Eugenia uniflora L.) e a jabuticaba (Myrciaria jaboticaba (Vell.) Berg) são amplamente difundidas no mercado, mas representam uma pequena fração do potencial econômico desta família, visto que uma grande quantidade de frutos é produzida por espécies não comerciais ou pouco conhecidas (FERREIRA et al., 2016), como a Campomanesia guazumifolia (Cambess.) O. Berg.

A espécie Campomanesia guazumifolia (Cambess.) O. Berg (Figura 1) comumente conhecida por sete-capotes, distribui-se de forma natural no Nordeste da Argentina, Leste do Paraguai e no Brasil, do Rio Grande do Sul a Bahia (LIMA; GOLDENBERG; SOBRAL, 2011). A espécie se apresenta na forma de arbustos ou árvores, possui frutos pequenos, do tipo baga, subglobosos, de cor verde-amarelado quando atingem a maturação, sua casca possui sabor amargo, porém sua polpa é carnosa e apresenta aroma intenso e agradável (CARVALHO, 2008; LORENZI, 2002).

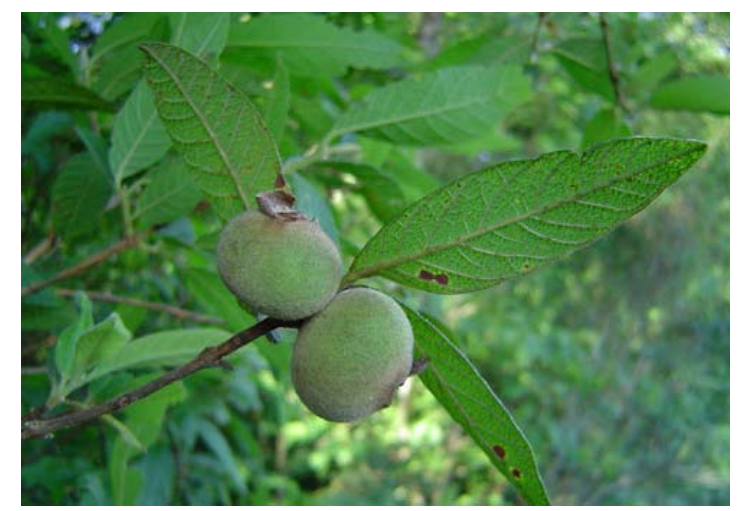

Figura 1. Campomanesia guazumifolia (Cambess.) O.Berg. Fonte: ROTHER, 2008.

Atualmente, o interesse pelos frutos das espécies da família das Mirtáceas tem aumentado, devido a seu aroma exótico, baixo custo, alto teor de vitaminas e ampla aplicabilidade industrial (MARIN et al. 2008). Destaca-se também a presença de óleos essenciais, metabólitos secundários de elevado impacto odorífero, que além de contribuírem para o aroma dos frutos, apresentam atividade antibacteriana, antiinflamatória, fungicida, antiviral e antioxidante (SIDDIQUE et al. 2017).

O odor dos frutos de diversas espécies da família das Mirtáceas, está relacionado a compostos voláteis como ésteres, aldeídos, álcoois, terpenos e seus derivados (FERREIRA et al., 2016; JÓRDAN et al., 2003; OLIVEIRA et al., 2006; QUIJANO; PINO, 2007), constituintes que vem a contribuir significativamente para a caracterização e identificação da espécie vegetal, como também em sua avaliação sensorial e aceitação pelos consumidores (BICAS et al., 2011). Entretanto, não foram encontrados na literatura estudos a respeito da caracterização da fração volátil dos frutos de Campomanesia guazumifolia (Cambess.) O. Berg.

Desse modo, o objetivo do presente trabalho foi realizar a caracterização dos compostos voláteis da polpa e do óleo essencial das cascas e sementes dos frutos de sete-capotes. 


\section{Material e Métodos}

\subsection{Material}

Os frutos de sete-capotes foram colhidos em dezembro de 2011 na cidade de Tuparendi, Rio Grande do Sul, Brasil, localizada na latitude $27^{\circ} 51^{\prime} 52,47^{\prime \prime}$ Sul, longitude $54^{\circ} 28^{\prime} 10,30^{\prime \prime}$ oeste. As amostras foram mantidas congeladas a $-20^{\circ} \mathrm{C}$ até a realização das análises. Anteriormente a extração dos compostos voláteis da polpa e dos óleos essenciais, os frutos foram descascados congelados e a polpa separada das sementes manualmente. Após, a polpa foi homogeneizada em multiprocessador e centrifugada a $670 \times g$ em centrífuga MTD III Plus (Logen Cientific, Brasil). Parte do sobrenadante da polpa centrifugada foi disposto em frasco de amostragem de headspace, já as cascas e sementes destinadas a extração dos óleos essenciais.

\subsection{Métodos}

\subsubsection{Extração dos compostos voláteis da polpa}

Os compostos voláteis da polpa foram isolados pela técnica de microextração em fase sólida aplicada ao headspace (HS-SPME). Assim, cerca de $10 \mathrm{~mL}$ de amostra centrifugada foram adicionados de $3,0 \mathrm{~g}$ de $\mathrm{NaCl}$ em frasco âmbar de $20 \mathrm{~mL}$ e tampado com septo de PTFE. A extração foi realizada pela exposição da fibra DVB/Car/PDEM (Divinylbenzene/ Carboxen/Polydimethylsiloxane, 50/30 $\mu \mathrm{m} \times 20 \mathrm{~mm}$ ) (Supelco, Bellefonte, PA, USA) no headspace do frasco contendo a amostra por 45 min a $35^{\circ} \mathrm{C}$, sob agitação constante. A extração da amostra foi precedida de 5 min de equilíbrio sem a exposição da fibra, também sob agitação e mesma temperatura de extração.

\subsubsection{Análises cromatográficas dos compostos voláteis da polpa}

A análise quantitativa dos compostos voláteis (CV) foi realizada em um cromatógrafo a gás equipado com detector de ionização em chama (CG-DIC) da marca Varian, modelo Star 3400CX (CA, USA). Os compostos voláteis da fibra de SPME foram dessorvidos termicamente em um injetor do tipo split/splitless, operando no modo splitless (por $2 \mathrm{~min}$ ) e temperatura de $230^{\circ} \mathrm{C}$. A fibra permaneceu exposta no injetor nestas condições por 10 min para minimizar o efeito carry-over de uma amostra para outra. A separação dos CV ocorreu em uma coluna capilar CP-WAX (Middelburg, Netherlands) $(60 \mathrm{~m} \times 0,25 \mathrm{~mm} \times 0,25 \mu \mathrm{m})$. A temperatura inicial da coluna foi mantida a $35^{\circ} \mathrm{C}$ por 1 min e após foi aumentada até $120^{\circ} \mathrm{C}$ com a rampa de temperatura de 2 ${ }^{\circ} \mathrm{C} / \mathrm{min}$. Após a temperatura foi elevada a $230{ }^{\circ} \mathrm{C}$ com rampa de $5{ }^{\circ} \mathrm{C} / \mathrm{min}$, onde permaneceu em isoterma por 5 min. Foi utilizado gás hidrogênio como gás de arraste com pressão constante de 30 psi. A temperatura do detector de ionização em chama foi mantida a $250{ }^{\circ} \mathrm{C}$. Os resultados foram expressos em áreas percentuais da área total do cromatograma.

A análise qualitativa foi realizada em um cromatógrafo a gás acoplado a um espectrômetro de massas (CG/EM) da marca Shimadzu, modelo CG/EM QP-2010 Plus (Kyoto, Japan), utilizando a mesma coluna e condições cromatográficas descritas anteriormente, porém o gás hélio foi utilizado como gás de arraste. O detector de massas foi operado no modo de ionização por elétrons $\mathrm{a}+70 \mathrm{eV}$, com o analisador de massas do tipo quadrupolo no modo de varredura na faixa de 35 a $350 \mathrm{~m} / \mathrm{z}$. A identificação dos compostos voláteis foi realizada através da comparação dos espectros de massas com aqueles fornecidos pela biblioteca NIST, além da 
comparação dos índices de Kovats experimentais com os disponíveis na literatura (ACREE; HEINRICH, 2004; EL-SAYED, 2013).

\subsubsection{Extração dos óleos essenciais das cascas e sementes}

Os óleos essenciais foram extraídos por hidrodestilação em aparato do tipo Clevenger por $3 \mathrm{~h}$. Para a extração das cascas foram utilizados $100 \mathrm{~g}$ de amostra e $400 \mathrm{~mL}$ de água destilada, já para as sementes $50 \mathrm{~g}$ de amostra e $300 \mathrm{~mL}$ de água destilada. Os óleos essenciais extraídos foram acondicionados em frascos do tipo Eppenford e armazenados $\mathrm{a}-20^{\circ} \mathrm{C}$ até a realização das análises.

\subsubsection{Análises cromatográficas dos óleos essenciais das cascas e sementes}

A quantificação foi realizada pela injeção de $1 \mu \mathrm{L}$ de óleo essencial diluído em hexano na proporção de 1:100 (volume/volume) em cromatógrafo a gás equipado com detector de ionização em chama (CG-DIC) da marca Varian, modelo Star 3400 (CA, USA. Os analitos foram separados em coluna capilar RTX-5EM (Restek-USA) (30 m $\times$ $0,25 \mathrm{~mm} \times 0,25 \mu \mathrm{m})$. O gás de arraste utilizado foi o hidrogênio à pressão constante de 25 psi. O injetor manteve-se no modo split com razão 30:1 e temperatura de 250 ${ }^{\circ} \mathrm{C}$. A temperatura inicial da coluna foi de $50{ }^{\circ} \mathrm{C}$, onde permaneceu por $1 \mathrm{~min}$, aumentando para $100{ }^{\circ} \mathrm{C}$ com taxa de $3^{\circ} \mathrm{C} / \mathrm{min}$. Após, com taxa de $1{ }^{\circ} \mathrm{C} / \mathrm{min}$ até atingir $125^{\circ} \mathrm{C}$ e então até $230^{\circ} \mathrm{C}$ com taxa de $15^{\circ} \mathrm{C} / \mathrm{min}$ mantendo-se em isoterma por 5 min. O detector manteve-se na temperatura de $230{ }^{\circ} \mathrm{C}$. Os resultados foram expressos em áreas percentuais da área total do cromatograma.

A identificação dos compostos foi realizada pela análise em cromatógrafo a gás acoplado a um espectrômetro de massas (CG/EM) da marca Shimadzu, modelo CG/EM QP-2010 Plus (Shimadzu Corporation, Kyoto, Japan), utilizando a mesma coluna e condições cromatográficas descritas anteriormente, já o gás hélio foi utilizado como gás de arraste. O detector de massas foi operado no modo de ionização por elétrons a $+70 \mathrm{eV}$, com o analisador de massas do tipo quadrupolo no modo de varredura na faixa de 35 a $350 \mathrm{~m} / \mathrm{z}$. A identificação dos compostos voláteis foi realizada através da comparação dos espectros de massas com aqueles fornecidos pela biblioteca NIST, além da comparação dos índices de Kovats experimentais com os disponíveis na literatura (ACREE; HEINRICH, 2004; EL-SAYED, 2013).

\section{Resultados e Discussão}

\subsection{Compostos voláteis da polpa}

Na polpa de sete-capotes foram detectados 175 picos por CG- DIC e destes, 81 foram identificados por CG/EM. Os compostos identificados foram classificados em sete classes químicas: terpenos (29 compostos), álcoois (16 compostos), ésteres (15 compostos), aldeídos (8 compostos), cetonas (7 compostos), ácidos (5 compostos) e furano (1 composto) (Tabela 1). Os compostos majoritários na polpa de sete-capotes foram o 1- hexanol (19,28\%), hexanal (13,82\%), (E)-2-hexenol (8,48\%), etanol (7,11\%), ácido hexanoico (4,74\%), (E)-2-hexenal (4,65\%), (Z)-3-hexenol (3,38\%), (E) $\beta$-ocimeno (3,15\%), acetato de etila (2,24\%) e o mentol (2,35\%) (Figura 2$)$.

Tabela 1. Compostos voláteis da polpa dos frutos de sete-capotes.

\begin{tabular}{cccc}
\hline IK exp. & Composto & Área* $^{*}$ & Área Relativa \\
\hline \multicolumn{4}{c}{ Terpenos } \\
\end{tabular}




\begin{tabular}{|c|c|c|c|}
\hline 1151 & $\alpha$ felandreno & 3,12 & 0,15 \\
\hline 1155 & $\beta$ mirceno & 4,25 & 0,2 \\
\hline 1183 & Limoneno & 3,94 & 0,19 \\
\hline 1191 & Sabineno & 1,17 & 0,06 \\
\hline 1197 & 1,8 cineol & 13,12 & 0,63 \\
\hline 1225 & (Z) ocimeno & 0,53 & 0,03 \\
\hline 1242 & (E) $\beta$ ocimeno & 65,26 & 3,15 \\
\hline 1435 & (Z) óxido de linalol & 2,99 & 0,14 \\
\hline 1547 & Linalol & 39,78 & 1,92 \\
\hline 1559 & (Z) sabineno & 1,18 & 0,06 \\
\hline 1581 & (E) $\beta$ cariofileno & 3,4 & 0,16 \\
\hline 1599 & Terpineol & 30,29 & 1,46 \\
\hline 1644 & Mentol & 2,7 & 0,13 \\
\hline 1662 & a humuleno & 2,06 & 0,1 \\
\hline 1667 & $\beta$ ferneseno & 3,03 & 0,15 \\
\hline 1732 & (E) oxido de linalol & 1,15 & 0,06 \\
\hline 1749 & Farneseno & 2,49 & 0,12 \\
\hline 1752 & $\delta$ cadineno & 11,42 & 0,55 \\
\hline 1781 & L-mentol & 48,73 & 2,35 \\
\hline 1788 & $\mathrm{Y}$ isogeraniol & 2,02 & 0,1 \\
\hline 1808 & Isogeraniol & 5,22 & 0,25 \\
\hline 1822 & (E) carveol & 3,96 & 0,19 \\
\hline 2024 & $\beta$ nerolidol & 3,41 & 0,16 \\
\hline 2037 & Cubenol & 2,51 & 0,12 \\
\hline 2041 & Epicubenol & 5,24 & 0,25 \\
\hline 2047 & Globuol & 1,43 & 0,07 \\
\hline 2129 & Elemol & 2,72 & 0,13 \\
\hline 2140 & Espatulenol & 0,45 & 0,02 \\
\hline 2201 & a cadinol & 4,09 & 0,2 \\
\hline Área Total & & 271,66 & 13,1 \\
\hline \multicolumn{4}{|c|}{ Álcoois } \\
\hline 935 & 2-propanol & 0,86 & 0,04 \\
\hline 944 & Etanol & 147,41 & 7,11 \\
\hline 1049 & 3-metil-2-buten-1-ol & 37,02 & 1,79 \\
\hline 1172 & Penten-3-ol & 12,16 & 0,59 \\
\hline 1267 & 1-pentanol & 6,53 & 0,31 \\
\hline 1317 & (Z)-2-penten-1-ol & 19,66 & 0,95 \\
\hline 1353 & 1-hexanol & 399,75 & 19,28 \\
\hline 1361 & (E)-3-hexen-1-ol & 41,06 & 1,98 \\
\hline 1380 & (Z)-3-hexen-1-ol & 70 & 3,38 \\
\hline 1402 & (E)-2-hexen-1-ol & 175,92 & 8,48 \\
\hline 1405 & 5-hexen-1-ol & 4,04 & 0,19 \\
\hline 1410 & (Z)-2-hexen-1-ol & 4,71 & 0,23 \\
\hline 1483 & 2-etil-1-hexanol & 9,21 & 0,44 \\
\hline 1542 & 2,3-butanediol & 4,04 & 0,19 \\
\hline
\end{tabular}




$\begin{array}{llcc}1556 & \text { 1-octanol } & 1,88 & 0,09 \\ 1650 & \text { 4-nonanol } & 5,04 & 0,24 \\ \text { Área Total } & & 939,27 & 45,3\end{array}$

$\begin{array}{llcc}834 & \text { Acetato de metila } & 2,12 & 0,1 \\ 895 & \text { Acetato de etila } & 51,81 & 2,5 \\ 1020 & \text { Acetato de isobutila } & 10,34 & 0,5 \\ 1043 & \text { Butanoato de etila } & 40,3 & 1,94 \\ 1080 & \text { Acetato de butila } & 1,85 & 0,09 \\ 1167 & \text { 2-butanoato de etila } & 18,87 & 0,91 \\ 1185 & \text { Hexanoato de metila } & 14,98 & 0,72 \\ 1230 & \text { Hexanoato de etila } & 15,48 & 0,75 \\ 1293 & \text { Acetato de hexila } & 29,48 & 1,42 \\ 1299 & \text { (Z)-3-hexanoato de etila } & 2,19 & 0,11 \\ 1296 & \text { 3-hexanoato de etila } & 0,51 & 0,02 \\ 1308 & \text { Acetato de (Z)-3- hexen-1- } & 17,58 & 0,85 \\ 1327 & \text { ol } & 9,6 & 0,46 \\ 1515 & \text { Acetato de (E)-2-hexenil } & 9,67 & 0,38 \\ 1627 & \text { 3-hidroxibutanoato de etila } & 7,87 & 0,36 \\ \text { Área Total } & \text { Benzoato de metila } & 7,39 & 11,11\end{array}$

Aldeídos

$\begin{array}{llcc}817 & \text { 2-metil propanal } & 6,69 & 0,32 \\ 888 & \text { 2-metil 2-propenal } & 7,47 & 0,36 \\ 918 & \text { 2-metil butanal } & 2,55 & 0,12 \\ 922 & \text { 3-metil butanal } & 2,68 & 0,13 \\ 1091 & \text { Hexanal } & 286,45 & 13,82 \\ 1220 & \text { (E) 2-hexenal } & 96,43 & 4,65 \\ 1491 & \text { (E) 2,4-heptadienal } & 4,07 & 0,2 \\ 1520 & \text { Benzaldeido } & 0,97 & 0,05 \\ \text { Área Total } & & 407,3 & 19,64\end{array}$

Cetonas

823

909

984

1258

1296

1660

1675

Área Total

\section{2-propanona}

2-butanona

2-pentanona

3-octanona

3-hidroxi-2-butanona

1-fenil etanona

Criptona
18,2

1,16

20,48

16,79

3,86

1,67

2,64

64,79
0,88

0,06

0,99

0,81

0,19

0,08

0,13

3,12

Ácidos 


$\begin{array}{llcc}1824 & \text { Ácido hexanoico } & 98,34 & 4,74 \\ 1938 & \text { (E) 2-ácido hexanoico } & 26,85 & 1,29 \\ 2032 & \text { Ácido octanoico } & 2,77 & 0,13 \\ 2167 & \text { Ácido nonanoico } & 1,17 & 0,06 \\ \text { Área Total } & & 140,92 & 6,8\end{array}$

\section{Furano}

1162

2- propil furano

19,1

0,92

Área Total

19,1

0,92

IK Exp. - Índice de Kovats experimental

Área* - área $\times 10^{-4}$

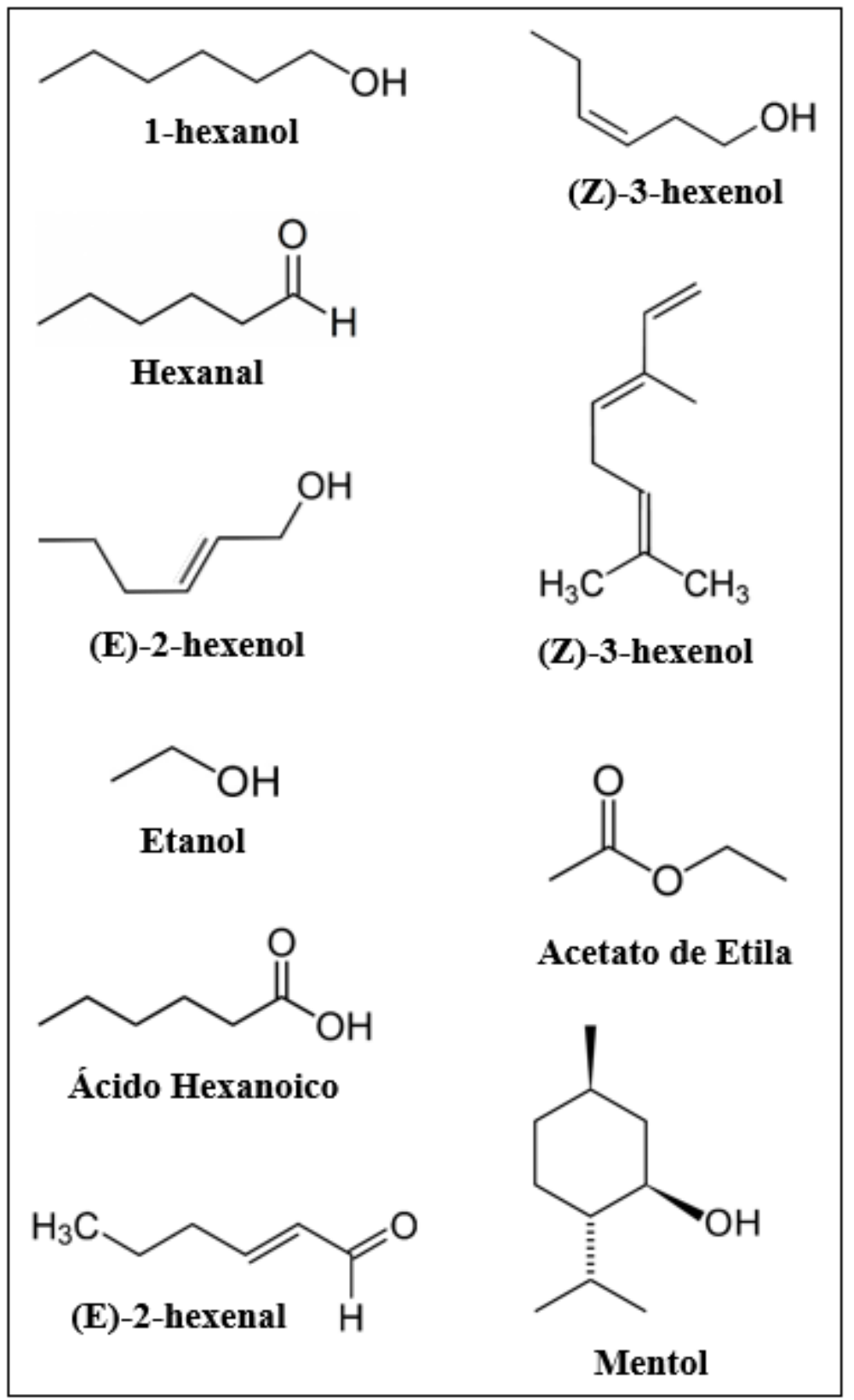

Figura 2. Estruturas químicas dos compostos majoritários da fração volátil da polpa de sete-capotes. 
A classe dos terpenos foi a que apresentou o maior número de compostos na fração volátil da polpa de sete-capotes determinados pela técnica de HS-SPME. Os terpenos são comumente encontrados em frutos da família das Mirtáceas, visto que estes apresentam capacidade de síntese e armazenamento de óleos essenciais principalmente em suas cascas e sementes (FIGUEIREDO et al., 2008). Os terpenos são formados a partir do metabolismo de carboidratos através da via isoprenoide ou ainda pela degradação de carotenoides (THOLL, 2006).

O terpeno majoritário presente na polpa de sete-capotes, o (E) $\beta$-ocimeno também foi reportado por Oliveira et al. (2006) como um dos compostos majoritários desta classe em pitangas. Apesar de o (E) $\beta$-ocimeno apresentar maior área, outros terpenos identificados na polpa de sete-capotes são reportados por apresentam impacto odorífero superior, como L-mentol, linalol e 1,8-cineol, que apresentam odor de menta, floral e eucalipto, respectivamente (AMIRA et al., 2011; MARIN et al., 2008; OLIVEIRA et al., 2006). Nos frutos de sete-capotes, esses compostos podem estar contribuindo com notas de odor herbáceo, floral e amadeirado.

Por outro lado, a classe majoritária da fração volátil em relação à área total dos compostos foi a dos álcoois (45,30\%), seguida pelos aldeídos (19,64\%). A formação dos álcoois, aldeídos, como também das cetonas ocorre pelo metabolismo de ácidos graxos através da via das lipoxigenases. Essa via de degradação origina compostos C6, C8 e C9, os compostos C6 e C9 são aldeídos e álcoois primários, enquanto os compostos C8 são cetonas e álcoois secundários, já que os aldeídos e cetonas são convertidos em álcoois correspondentes, que, normalmente, apresentam limiar de detecção mais elevado e odores mais fortes do que os compostos carbonílicos precursores. E os álcoois, por sua vez, originam os ésteres (DAMODARAN; PARKIN; FENNEMA, 2010; ZHANG et al., 2009).

Dentre os álcoois foram detectados em maior concentração o 1-hexanol (19,28\%), o (E)-2-hexen-ol (8,48\%) e o (Z)-3-hexen-1-ol (3,38\%), já reportados como álcoois majoritários em frutos de goiaba (SCHREIER; IDSTEIN, 1985). Além destes, o etanol apresentou elevada concentração $(7,11 \%)$, entretanto, pode ser proveniente da fermentação dos frutos durante as etapas do preparo de amostra.

O aldeído encontrado em maior concentração na fração volátil da polpa de setecapotes, o hexanal também foi reportado por Macleod e Troconis (1982) como um dos compostos majoritários encontrados na composição volátil de goiaba. Além do hexanal, vários outros compostos C6, C8 e C9 provenientes da via das lipoxigenases são encontrados em abundância em outras mirtáceas como goiaba (JÓRDAN et al., 2003), pitanga (OLIVEIRA et al., 2006), jabuticaba (PLAGEMANN et al., 2012) e araçá (PINO; MARBOT; VÁZQUEZ, 2001).

Embora os álcoois e aldeídos contribuam diretamente para o odor de frutas, os ésteres podem representar até $98 \%$ dos voláteis totais emitidos por frutas maduras sadias e são responsáveis por notas frutais e doces (VILLATORO et al., 2008). Os ésteres podem ser formados a partir dos álcoois e estes por sua vez são provenientes da degradação de ácidos graxos ou ainda de aminoácidos. Dentre os ésteres destacaram-se o acetato de etila e o butanoato de etila.

A composição volátil da polpa de sete-capotes se assemelha qualitativamente a da Campomanesia xantocarpa, comumente conhecida como guabiroba. Alguns dos compostos 10 majoritários são comuns às duas espécies, como (E)-2-hexenal, etanol, hexanal, ácido hexanoico, 1-hexanol e (E)-2-hexenol (FERREIRA et al., 2016). Neste mesmo estudo, foi realizada a análise olfatométrica através da técnica Osme e os 
provadores associaram os aldeídos principalmente a notas verdes, já os álcoois receberam uma variedade de descrições como plástico, remédio, queimado, verde e floral.

\subsection{Composição química dos óleos essenciais}

A extração em aparato do tipo Clevenger foi realizada para as cascas, sementes e também para polpa dos frutos de sete-capotes, entretanto apenas cascas e sementes apresentaram óleos essenciais. A partir de $3 \mathrm{~h}$ foi atingindo o rendimento máximo na extração, $0,3 \%$ para as cascas e $1 \%$ para as sementes em base úmida. A quantidade de óleo essencial obtida para as cascas está de acordo com dados reportados na literatura para frutos de guabiroba (0,31\%) (OLIVEIRA et al., 2017), de jaboticaba $(0,37 \%)$ (DUARTE et al., 2010) e de pitanga (0,30\%) (RODRIGUES et al., 2013). Rendimentos superiores foram encontrados para goiaba (0,6\%) (FASOLA; OLOYEDE; BABALOLA, 2011) e para araçá (0,8\%) (ADAM et al., 2011), mas ainda inferiores aos obtidos para sementes de sete-capotes.

Foram detectados cerca de 60 compostos nos óleos essenciais de sete-capotes, destes 24 foram identificados por CG/EM (Tabela 2). Os óleos essenciais das cascas e sementes apresentaram uma predominância de monoterpenos hidrocarbônicos $(82,25$ e $72,53 \%$, respectivamente), seguida por sesquiterpenos oxigenados $(14,50$ e 18,70\%, respectivamente), sesquiterpenos hidrocarbônicos (1,90 e 7,89, respectivamente) e baixas concentrações de monoterpenos oxigenados (1,35 e $0,88 \%$, respectivamente).

Qualitativamente os óleos essenciais das cascas e sementes foram semelhantes, os compostos majoritários foram o $\beta$-ocimeno ( $Z$ ), o nerolidol (E) e o limoneno. Foram observadas diferenças na concentração dos compostos entre os óleos obtidos, principalmente para os compostos a-copaeno, $\alpha$-umuleno, $\alpha$-amorfeno e $\gamma$-cadineno, presentes em concentrações superiores no óleo das sementes. Limberger et al. (2001) extraíram óleo essencial das folhas de sete-capotes e os compostos majoritários foram o nerolidol (E) $(28,8 \%)$, espatulenol $(27,7 \%)$ e mirceno $(11,5 \%)$.

Tabela 2. Principais compostos do óleo essencial da casca e da semente de setecapotes.

\begin{tabular}{|c|c|c|c|c|c|}
\hline IK.exp & Composto & Área $a^{*}$ & Área Relativa a & Área b* & $\begin{array}{c}\text { Área Relativa } \\
\text { b }\end{array}$ \\
\hline \multicolumn{6}{|c|}{ Monoterpenos Hidrocarbônicos } \\
\hline 923 & a-tujeno & 9,68 & 0,24 & 10,55 & 0,23 \\
\hline 930 & a-pineno & 92,36 & 2,29 & 86,31 & 1,84 \\
\hline 987 & Mirceno & 37,15 & 0,92 & 34,98 & 0,75 \\
\hline 998 & a-felandreno & 141,41 & 3,51 & 162,72 & 3,47 \\
\hline 1020 & p-cimeno & 46,43 & 1,15 & 26,91 & 0,57 \\
\hline 1025 & Linoneno & 459,1 & 11,39 & 434,48 & 9,27 \\
\hline 1049 & $\beta$-ocimeno (Z) & 2525,81 & 62,66 & 2621,06 & 55,92 \\
\hline 1363 & a-copaeno & 3,65 & 0,09 & 22,51 & 0,48 \\
\hline \multicolumn{6}{|c|}{ Monoterpenos Oxigenados } \\
\hline 1379 & p-menta-2,8-dien1-ol & 54,25 & 1,35 & 41,32 & 0,88 \\
\hline
\end{tabular}

Sesquiterpenos Hidrocarbônicos 


\begin{tabular}{|c|c|c|c|c|c|}
\hline 1404 & Cariofileno (E) & 40,06 & 0,99 & 116,68 & 2,49 \\
\hline 1438 & a-umuleno & 10,89 & 0,27 & 68,88 & 1,47 \\
\hline 1464 & a-amorfeno & 7,96 & 0,20 & 40,92 & 0,87 \\
\hline 1498 & Y-cadineno & 11,31 & 0,28 & 98,1 & 2,09 \\
\hline 1522 & a-cadineno & 2,62 & 0,06 & 25,98 & 0,55 \\
\hline 1538 & Germacreno B & 3,83 & 0,10 & 19,5 & 0,42 \\
\hline \multicolumn{6}{|c|}{ Sesquiterpenos Oxigenados } \\
\hline 1557 & Nerolidol (E) & 458,53 & 11,38 & 770,84 & 16,45 \\
\hline 1560 & Espatulenol & 32,03 & 0,79 & 7,99 & 0,17 \\
\hline 1564 & Óxido de cariofileno & 34,26 & 0,85 & 5,9 & 0,13 \\
\hline 1583 & $\begin{array}{l}\text { Viridiflorol } \\
\text { Epóxido de }\end{array}$ & 5,72 & 0,14 & 10,92 & 0,23 \\
\hline 1589 & humuleno & 5,99 & 0,15 & 5,79 & 0,12 \\
\hline 1596 & Epicubenol & 3,9 & 0,10 & 10,78 & 0,23 \\
\hline 1633 & 1,10-Di-epi-cubenol & 11,24 & 0,28 & 10,48 & 0,22 \\
\hline 1663 & a-muurolol & 8,71 & 0,22 & 16,47 & 0,35 \\
\hline 1672 & Cadin-4-en-10-ol & 24,05 & 0,60 & 37,23 & 0,79 \\
\hline
\end{tabular}

IK Exp. - Índice de Kovats experimental

Área $a^{*}$ - área compostos casca $\times 10^{-3}$

Área $b^{*}$ - área compostos semente $\times 10^{-3}$

As mirtáceas são amplamente utilizadas na medicina popular, devido a isso muitos trabalhos estão verificando a atividade biológica das espécies pertencentes a esta família. Foram verificadas propriedades antifúngicas, antibacterianas e antioxidantes, tais bioatividades estão sendo relacionadas aos terpenos oxigenados (STEFANELLO; PASCOAL; SALVADOR, 2011). Neste sentido o óleo essencial das sementes de setecapotes apresentou concentração superior de terpenos oxigenados $(19,58 \%)$ do que 0 óleo das cascas $(14,50 \%)$.

\section{Conclusão}

Através da análise cromatográfica do headspace da polpa de sete-capotes por HSSPME foram identificados 81 compostos. A classe que apresentou maior número de compostos foi a dos terpenos, porém foram álcoois e aldeídos que apresentam maior somatório de áreas no cromatograma. Os álcoois e aldeídos apresentam como característica notas verdes e possivelmente os responsáveis pelo odor herbáceo do sete-capotes.

As cascas e principalmente as sementes de sete-capotes se mostraram uma fonte abundante de óleos essenciais, os quais são constituídos majoritariamente por monoterpenos hidrocarbônicos. Alguns dos terpenos encontrados nos óleos essenciais também foram detectados no headspace da polpa dos frutos de setecapotes e podem estar relacionados a notas amadeiradas e florais.

\section{Referências}

ACREE, T.E.; HEINRICH, A. Flavornet and human odor space, gas chromatography -olfactometry (CG-O) of natural products. 2004. Disponível em: http://www.flavornet.org/f_kovats.html. Acesso em: 18 set 2017. 
ADAM, F. et al. Aromatic plants of French Polynesia. V. Chemical composition of essential oils of leaves of Psidium guajava L. and Psidium cattleyanum Sabine. Journal of Essential Oil Research, v. 23, n. 1, p. 98-101, 2011. https://doi.org/10.1080/10412905.2011.9700433.

AMIRA, E. A. et al. Chemical and aroma volatile compositions of date palm (Phoenix dactylifera L.) fruits at three maturation stages. Food Chemistry, v. 127, p. 17441754, 2011. https://doi.org/10.1016/j.foodchem.2011.02.051.

AYSELI, M. T.; AYSELI, Y. İ. Flavors of the future: health benefits of flavor precursors and volatile compounds in plant foods. Trends in Food Science \& Technology, v. 48, p. 69-77, 2016. https://doi.org/10.1016/j.tifs.2015.11.005.

CARVALHO, P. E. R. Espécies arbóreas brasileiras. 1. ed. Brasília: Embrapa Informação Tecnológica, v. 3, 2008. 593 p.

DAMODARAN, S.; PARKIN, K. L.; FENNEMA, O. R. Química de alimentos de Fennema. Porto Alegre: Artemed, p. 517, 2010.

DUARTE, A. R. et al. Environmental influence on phenols and essential oils of Myrciaria cauliflora leaves. Journal of the Brazilian Chemical Society, v. 21, n. 9, 1672-1680, 2010. https://doi.org/10.1590/S0103-50532010000900011.

EL-SAYED, A. M. The pherobase. Disponível em:

http://www.pherobase.com/database/kovats/kovats-index.php. Acesso em: 18 set 2013.

FASOLA, T. R.; OLOYEDE, G. K.; APONJOLOSUN, B. S. Chemical composition, toxicity and antioxidant activities of essential oils of stem bark of Nigerian species of Guava (Psidium guajava Linn.). Excli Journal, v.10, p. 34-43, 2011.

FERREIRA, D. D. F. et al. Characterization of odor-active compounds in gabiroba fruits (Campomanesia xanthocarpa O. Berg). Journal of Food Quality, v. 39, p. 90-97, 2016. https://doi.org/10.1111/jfq.12177.

FIGUEIREDO, A. C. et al. Factors affecting secondary metabolite production in plants: volatile components and essential oils. Flavour and Fragance Journal, v. 23, p. 213226, 2008. https://doi.org/10.1002/ffj.1875.

INFANTE, J. et al. Antioxidant and anti-inflammatory activities of unexplored Brazilian

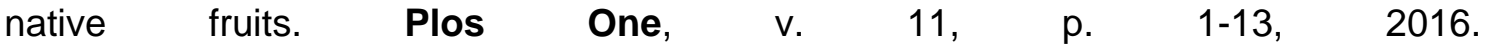
https://doi.org/10.1371/journal.pone.0152974.

LIMA, D. F.; GOLDENBERG, R.; SOBRAL, M. O gênero Campomanesia (Myrtaceae) no estado do Paraná, Brasil. Rodriguésia, v. 62, p. 683-693, 2011. https://doi.org/10.1590/2175-7860201162313.

LIMBERGER, R. P. et al. Chemical composition of essential oils from some Campomanesia Species (Myrtaceae). Journal of Essential Oil Research, v. 13, n. 2, p. 113-115, 2001. https://doi.org/10.1080/10412905.2001.9699630.

LORENZI, H. Árvores brasileiras: manual de identificação e cultivo de plantas arbóreas nativas do Brasil, v. 1. Nova Odessa: Instituto Plantarum, 2002. 368p. 
MACLEOD, A. J.; TROCONIS, N. G. Volatile flavour components of guava. Phytochemistry, v. 21, p. 1339-1342, 1982 . https://doi.org/10.1016/00319422(82)80138-6.

MARIN, R. et al. Volatile components and antioxidant activity from some Myrtaceous fruits cultivated in Southern Brazil. Latin American Journal of Pharmacy, v.27, p.172177, 2008.

OLIVEIRA, A. L. et al. Volatile compounds from pitanga fruit (Eugenia uniflora L). Food Chemistry, v. 99, n. 1, p. 1-5, 2006. https://doi.org/10.1016/j.foodchem.2005.07.012.

OLIVEIRA, J. D. et al. Chemical composition of essential oil extracted from leaves of Campomanesia adamantium subjected to different hydrodistillation times. Ciência Rural, v.47, n. 1, e20151131, 2017. https://doi.org/10.1590/0103-8478cr20151131.

PEREIRA, M. C. et al. Characterization and antioxidant potential of Brazilian fruits from the Myrtaceae family. Journal of Agricultural and Food Chemistry, v. 60, n. 12, p. 3061-3067, 2012. https://doi.org/10.1021/jf205263f.

PINO, J. A.; MARBOT, R.; VÁZQUEZ, C. Characterization of volatiles in strawberry guava (Psidium cattleianum Sabine) fruit. Journal of Agricultural and Food Chemistry, v. 49, p. 5883-5887, 2001. https://doi.org/10.1021/jf010414r.

PLAGEMANN, I. et al. Volatile constituents of jabuticaba (Myrciaria jaboticaba (Vell.) O. Berg) fruits. Journal of Essential Oil Research, v. 24, p. 45-51, 2012. https://doi.org/10.1080/10412905.2012.645651.

QUIJANO, C. E.; PINO, J. Analysis of volatile compounds of camu-camu (Myrciaria dubia (HBK) McVaugh) fruit isolated by different methods. Journal of Essential Oil Research, v. 19, p. 527-533, 2007. https://doi.org/10.1080/10412905.2007.9699323.

RODRIGUES, K. A. F. et al. Eugenia uniflora L. essential oil as a potential antileishmania agent: effects on Leishmania amazonensis and possible mechanis of action. Journal of Evidence-Based Complementary Alternative Medicine, v. 2013, p. 1-10, 2013. https://doi.org/10.1155/2013/279726.

ROTHER, M. S. Campomanesia guazumifolia (Cambess.) O.Berg. 2008. Disponível em: http://www.ufrgs.br/fitoecologia/florars/open_sp.php?img=394. Acesso em: 05 dez 2013.

SCHREIER, P.; IDSTEIN, H. Volatile constituents from Guava (Psidium guajava L.) fruit. Journal of Agricultural and Food Chemistry, v.33, p.138-143, 1985. https://doi.org/10.1021/jf00061a039.

SIDDIQUE, S. et al. Chemical composition and insecticidal activities of essential oils of Myrtaceae against Tribolium castaneum (Coleoptera: Tenebrionidae). Journal of

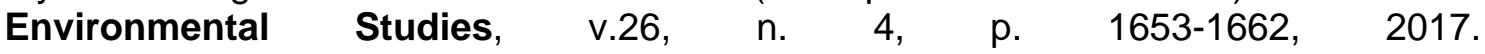
https://doi.org/10.15244/pjoes/73800.

STEFANELLO, M. E. A.; PASCOAL, A. C. R. F.; SALVADOR, M. J. Essential oils from neotropical Myrtaceae: chemical diversity and biological properties. Chemistry \& Biodiversity, v. 8, p. 73-94, 2011. https://doi.org/10.1002/cbdv.201000098. 
THOLL, D. Terpene synthases and the regulation, diversity and biological roles of terpene metabolism. Current Opinion in Plant Biology, v. 9, p. 297-304, 2006. https://doi.org/10.1016/j.pbi.2006.03.014.

VILLATORO, C. et al. Changes in biosynthesis of aroma volatile compounds during ontree maturation of "Pink Lady" apples. Postharvest Biology and Technology, v. 47, p. 286-295, 2008. https://doi.org/10.1016/j.postharvbio.2007.07.003.

ZHANG, X. R. et al. Lipoxygenase gene expression in ripening kiwifruit in relation to ethylene and aroma production. Journal of Agricultural and Food Chemistry, v. 57, p. 2875-2881, 2009. https://doi.org/10.1021/jf9000378.

\section{Autores}

Raquel Guidetti Vendruscolo ${ }^{1}$, Roger Wagner ${ }^{2}$, Bruna Tischer $^{2}$, Daniele de Freitas Ferreira $^{2}$, Francine Novack Victoria ${ }^{3, *}$

1. Curso de Pós-Graduação Lato Sensu em Ciência dos Alimentos, Centro de Ciências Químicas, Farmacêuticas e de Alimentos, Universidade Federal de Pelotas, Campus Capão do Leão, Caixa Postal 354, CEP. 96010-900, Pelotas, RS, Brasil; Departamento de Tecnologia e Ciência de Alimentos, Universidade Federal de Santa Maria, Av. Roraima, Prédio 42, sala 3210 Camobi, CEP. 97105-900, Santa Maria, RS, Brasil.

2. Departamento de Tecnologia e Ciência de Alimentos, Universidade Federal de Santa Maria, Av. Roraima, Prédio 42, sala 3210, Camobi, CEP. 97105-900, Santa Maria, RS, Brasil.

3. Centro de Ciências Químicas, Farmacêuticas e de Alimentos, Universidade Federal de Pelotas, Campus Capão do Leão, Caixa Postal 354, CEP. 96010-900, Pelotas, RS, Brasil.

*Autor para correspondência: francinevictoria@yahoo.com.br 